\title{
Proje Yönetimi Bilgi Alanları İle Özgün Bir Projenin Geliştirilmesi: E-Okuma Takvimi
}

Ömer UYSAL ${ }^{1}$

\begin{abstract}
Özet
İlerleme, kalkınma ve sürekli gelişim tüm ülkelerin ortak amaçlarındandır. Bu doğrultuda ülkeler kendi başına veya uluslararası işbirliği içinde sahip olunan kaynakları ortaya koyarak projeler yürütmektedir. Proje mantığının gerekliliği eğitim ve öğrenme alanında da kendini göstermiş ve proje tabanlı ögrenme modeli ortaya konmuştur. Belirli bir ihtiyacın giderilmesi amacıyla hazırlanan proje, aynı zamanda etkili bir öğrenme sürecine dönüştürülebilmektedir. Zaman içerisinde projelerin etkili ve verimli bir şekilde tamamlanabilmesi için proje yönetimi anlayışına ihtiyaç duyulmuş ve proje yönetimi kavramı ortaya konulmuştur. Proje Yönetimi çok geniş bir beceri ağını içinde barındırmaktadır. Bu bağlamda proje tabanlı yapılan tüm araştırma ve uygulamalar için proje yönetimi konusunda gerekli bilgi, tutum ve becerilere sahip olunması uygun ve anlamlı olacaktır. Proje Yönetimi, en temel hali ile bilgi alanları ve belirli süreç gruplarından oluşmaktadır. Proje Yönetimi bilgi alanları; kapsam, iletişim, bütçe, zaman, insan kaynakları, tedarik, risk, kalite, paydaş ve entegrasyon yönetimi olarak belirtilebilir. Bu çalışmada belirtilen bilgi alanlarının tanımları yapılarak, bilgi alanlarına yönelik bilgiler verilmiştir. Bilgilerin daha kolay anlaşılabilmesi ve proje yönetimi bilgi alanlarının daha somut bir hale getirilebilmesi için özgün olarak geliştirilen bir EOkuma Takvimi projesi üzerinde örneklendirmeler yapılmıștır. Bu çalışmanın proje tabanlı uygulamalar yapan kişilere on farklı bilgi alanı ve bu alanların birbirleri ile etkileşim durumlarına yönelik farklı bir bakış açısı kazandırabileceği düşünülmektedir.
\end{abstract}

Anahtar Kelimeler: Proje, proje yönetimi, proje yönetimi bilgi alanları, E-Okuma Takvimi Projesi

\section{Development Of An Authentic Project By Project Management Knowledge Areas: E-Reading Calendar}

\begin{abstract}
Progress, improvement and sustainable development are the common goals of all countries. In this direction countries execute projects considering their different kind of resources such as budget, human resources, technological practice, raw material etc. nationally or internationally. The need of project logic impressed education and learning disciplines and project based learning emerged. The project addressing the needs can be transformed an effective learning process. The concept of project management emerged because sense of project management required to complete project effective and efficient. Project management contains skill networks in itself. In this context having required information, attitudes and skills about project management is appropriate and meaningful by whom carries out project based research or application. Project management basically includes knowledge areas and process groups. Project management knowledge areas are as follows: Scope, communication, budget, time, human resource, procurement, risk, quality, stakeholder and integration. In this paper knowledge areas are defined and explained. The explanations are illustrated by an authentic E-Reading Calendar project. This paper can be thought to achieve different point of view by whom carries out project based research or application about ten knowledge areas and interactions between each other.
\end{abstract}

Keywords: Project, project management, knowledge areas, E-Reading Calendar Project

\footnotetext{
${ }^{1}$ Dr., Anadolu Üniversitesi, Eğitim Bilimleri Enstitüsü, Bilgisayar ve Öğretim Teknolojileri Eğitimi, uysalomer@gmail.com
} 


\section{Giriş}

Tarım toplumunda ve sanayi toplumunda olduğu gibi bilgi toplumunun da kendisine has dinamikleri, özellikleri olmuştur. Bilgi mesleki anlamda merkeze yerleşmiş ve enformasyon zemininden bilgeliğe doğru bir zirve yapmıştır. Bilgi ve iletişim teknolojileri; bilginin saklanması, depolanması, görüntülenmesi, iletilmesi vb. ihtiyaçlar doğrultusunda ortaya çıkarılmış ve bu ihtiyaçlar doğrultusunda geliştirilmektedir. Bilgiye dayalı iş gücü ve üretim, yeni okuryazarlıklar ve farklı beceri alanları ortaya çıkarmıştır (OECD, 2017; P21, 2011; Gordon ve arkadaşları, 2009). Bu beceriler 21. Yüzyıl becerileri olarak tanımlanmıştır. Uzmanlar proje yönetebilmeyi bir 21. yüzyıl becerisi olarak ifade etmektedir (P21, 2009; Trilling ve Fadel, 2009: 107; PMI-EF, 2014 ve P21, 2015). Alanyazında proje yönetimi mısır piramitlerine kadar geriye gitse de (El-Marashly, 1990) asıl etkisini bilgi toplumunda gösterdiği söylenebilir. Proje yönetiminin temelini teşkil eden bilgi alanları da bu düşünceye bir kanıt olarak gösterilebilir. Bilgi çağında bilgisayar gibi internet gibi önemli yeniliklere bakıldığında bunların birer proje ürünü olduğu söylenebilir. Bu bağlamda proje yönetiminin önemli bir katma değer alanı olduğu ifade edilebilir.

Ülkemizde kamu kurum ve kuruluşlarında ve özellikle eğitim kurumlarında hazırlanan projelere ciddi bir yer verilmektedir (Ayas ve arkadaşları, 2013; Avcı ve arkadaşları, 2016; Aydın ve arkadaşları, 2018). Kamu kurum ve kuruluşları, özel işletmeler, dernekler, vakıflar, araştırma-geliştirme merkezleri proje çağrılarına çıkmakta, eğitim kurumlarında, öğrenme merkezlerinde proje yönetiminin dolaylı olarak çalıştı̆̆ proje tabanlı öğrenme uygulamaları gerçekleştirilmektedir (eTwinning, 2005; Yeşilay, 2016; YTB, 2017; GSB, 2018; MEB, 2018; PRODES, 2018; KOSGEB, 2018; TUA, 2018; Tübitak, 2018). Proje Yönetimi ile yakından ilgisi olan proje tabanlı öğrenme uygulaması etkili ve tercih edilen bir öğrenme yöntemi olarak kabul edilmektedir (Özdener ve Özçoban, 2004; Yalçın ve arkadaşları, 2009; Ay, 2013). Eğitim kurumlarında ve öğrenme merkezlerinde proje tabanlı öğrenme uygulamaları öğrenenlerin proje yönetimi konusundaki becerilerini geliştirmektedir.

Bütçe desteği verilen proje çağrıları sayesinde gerek ülkemizde gerekse dünyada insanlar proje üretimi ve yönetimi konusunda çok ciddi bir fırsat yakalamışlardır. Ancak başlanan projelerin yaklaşık \%20 si başarısızlıkla, yaklaşık \%50'si de sıkıntılı bir şekilde sonuçlandığı ifade edilmektedir (Pinto, 2010; Standish Group, 2014). Yapılan bir araştırmada, projelerin başarısız olmalarının en önemli nedeni olarak projelerin \%32'sinde proje yönetimi becerilerinin yetersizliği gösterilmiştir (Çankaya, 2006: 51 52). Farklı araştırmalarda iletişim, kapsam, planlama, risk, insan kaynakları ve tedarik gibi proje yönetimi bilgi alanları ile doğrudan ilişkili konular, en yaygın görülen başarısızlık sebepleri arasında gösterilmektedir (Budak, 2012; Suvac1, 2013). Bu gerçek göz önünde bulundurularak proje yönetimi ve proje yönetimi bilgi alanlarının doğru bir şekilde anlaşılması gerektiği söylenebilir. 
Araştırmanın Önemi: Proje yönetimi bilgi alanlarının bilinmesi ile eğitim kurumlarında gerek öğretmenler ve gerekse öğrenciler proje tabanlı öğrenme sürecine on farklı alan ve bu alanların birbirleri ile entegrasyonunu göz önünde bulundurabilecektir. İletişim, zaman, insan kaynakları, bütçe vb. bu alanlar aynı zamanda proje yönetimi becerilerinin de kaynağını oluşturmaktadır. Beceri kazanımlarına bağlı olarak projelerden daha başarılı sonuçlar alınabilecek ve bu sayede projeler kapsamında, zamanında, bütçesinde ve istenen kalite çıktıları ile birlikte tamamlanabilecektir. Tatlı (2016) tarafından yapılan araştırmada Öğretmenlerin proje geliştirme konusunda yardım almak istedikleri konular arasında ilk sırada $\% 61,7$ ile proje geliştirme süreci, dördüncü sırada $\% 34,4$ ile Proje yazma eğitimi ve beşinci sırada \%32,2 ile Proje yönetimi süreci görülmektedir. Ayrıca Öğretmenlerin projelerde görev almayı istememelerinin ilk nedeni olarak da \%33 ile Proje geliştirme ve yönetimi konusunda bilgi eksikliği gösterilmektedir. Araştırma belirtilen bu engellerin aşılmasında küçük bir katkı sağlayabilir.

Ülkelerin kalkınma ve gelişim yarışında, özellikle öğretmenlerimizin ve öğrencilerimizin proje uygulamalarına daha profesyonel olarak yaklaşmaları önemli bir kazanım olarak düşünülebilir. Son olarak, proje hazırlayan, geliştiren, proje tabanlı öğrenen kişiler veya öğrenciler, E-Okuma Takvimi projesinin bilgi alanları ile geliştirilmesi sürecini kendi alanlarına yansıtarak özgün yeni projelerin ortaya çıkmasını sağlayabilirler.

Araştırmanın amacı: Araştırmanın amacı, proje tabanlı öğrenme uygulaması yapan öğretmen ve öğrencileri proje yönetimi bilgi alanları konusunda bilgilendirebilmek ve özgün bir projenin proje yönetimi bilgi alanları dikkate alınarak nasıl geliştirilebileceğini gösterebilmektir. Makalenin kaleme alınmasına neden olan araştırma soruları şunlardır:

1. Proje yönetimi nedir? Proje tabanlı öğrenme için neden gereklidir?

2. Proje yönetimi bilgi alanları nelerdir ve bu bilgi alanları nasıl tanımlanmaktadır?

3. Proje yönetimi bilgi alanları dikkate alınarak bir proje geliştirilebilir mi? Proje yönetimi bilgi alanları ile özgün bir proje nasıl geliştirilebilir? Süreç içerisinde neler yapılmalıdır?

\section{Yöntem}

$\mathrm{Bu}$ araştırmada araştırmanın amacı doğrultusunda araştırma soruları oluşturulmuştur. 1. ve 2. Araştırma sorusu için alanyazın taraması yapılımış ve 3. Araştırma sorusunun yanıtlanabilmesi için bilgi alanları ile özgün bir projenin nasıl geliştirilebileceği verilen örnekler ile açıklanmaya çalışılmıştır. Araştırma kapsamında tümevarım yöntemi kullanılmıştır. Tümevarım yönteminde bütünü oluşturan tüm parçalar dikkate alınarak bütüne yönelik bir karar verilmektedir (Uyanık, 2012: 196). Araştırma sayesinde, gözlem ve deneyimler dikkate alınarak proje yönetimi bilgi alanları ile proje geliştirebilmenin mümkün olma durumu ele alınmıştır. Araştırmada her bir bilgi alanına yönelik örnek uygulamalar adım adım geliştirilerek tümevarım yöntemi kapsamında özgün bir projenin tüm bileşenleri oluşturulmaya çalışılmıştır. Araştırmanın bütünlüğünü koruması ve gerekli entegrasyonun sağlanabilmesi için uygulamalar tek bir projeye yönelik olarak gerçekleştirilmiştir. 


\section{Bulgular}

Araştırmanın bulguları, araştırma sorularının mantıksal sıralamasına uygun olarak aşağıda verilmiştir.

\section{Proje Yönetimi Nedir? Proje Tabanlı Öğrenme için Neden Gereklidir?}

Proje yönetimi, proje ihtiyaçlarını karşılamak amacıyla tüm bilgi, beceri, yöntem, araç ve tekniklerin proje etkinliklerine uygulanması olarak tanımlanmaktadır (PMI, 2013). Tıpkı eğitimöğrenme programlarında olduğu gibi proje yönetimi de bir ihtiyacı karşılamak amacıyla yapılmaktadır. Bu ihtiyacı karşılayabilmek için projenin başından sonunda kadar belirli bilgi alanlarındaki bilgi beceri, yöntem, araç ve tekniklerden yararlanılmaktadır. Alanlar kendine özgü işlevleri olmakla birlikte, birbirlerini doğrudan veya dolaylı bir şekilde etkilemektedir. Alanların proje yönetimine yönelik işlevi bilindiğinde, diğer alanlara ve dolayısıyla proje yönetimine yönelik etkileri de daha net bir şekilde kestirilebilir.

Proje yönetiminin en temel amacı hazırlanmış bir projeyi başarı ile tamamlayabilmektir. İşin merkezini bir projenin varlığı oluşturmaktadır. Günümüz küresel yarışları hem ülkeler hem de şirketler adına işgücünün niteliklerini değiştirmiştir. Proje merkezli çalışma bu değişimin en başat olanlarından biridir. Bu bağlamda eğitim programları da kendisini yenileyerek bu gereksinimi etkili bir şekilde karşlayabilmek için proje tabanlı öğrenmeyi uygulamaya başlamıştır. Proje tabanlı öğrenme çağdaş öğrenme yöntemlerinden problem tabanlı öğrenme, işbirlikçi öğrenme, sosyal öğrenme, buluş yoluyla öğrenme ve durumlu öğrenmeyi de içinde barındırabilmektedir (Larmer, Mergendoller ve Boss, 2015; Tuncer, 2009; Hernández-Ramos ve De La Paz, 2009; Krajcik ve Blumenfeld, 2005; Korkmaz, 2002). Şekil 1'de alanyazındaki farklı proje tabanlı öğrenme tanımlarına yönelik yapılan bir sınıflama görülmektedir. 


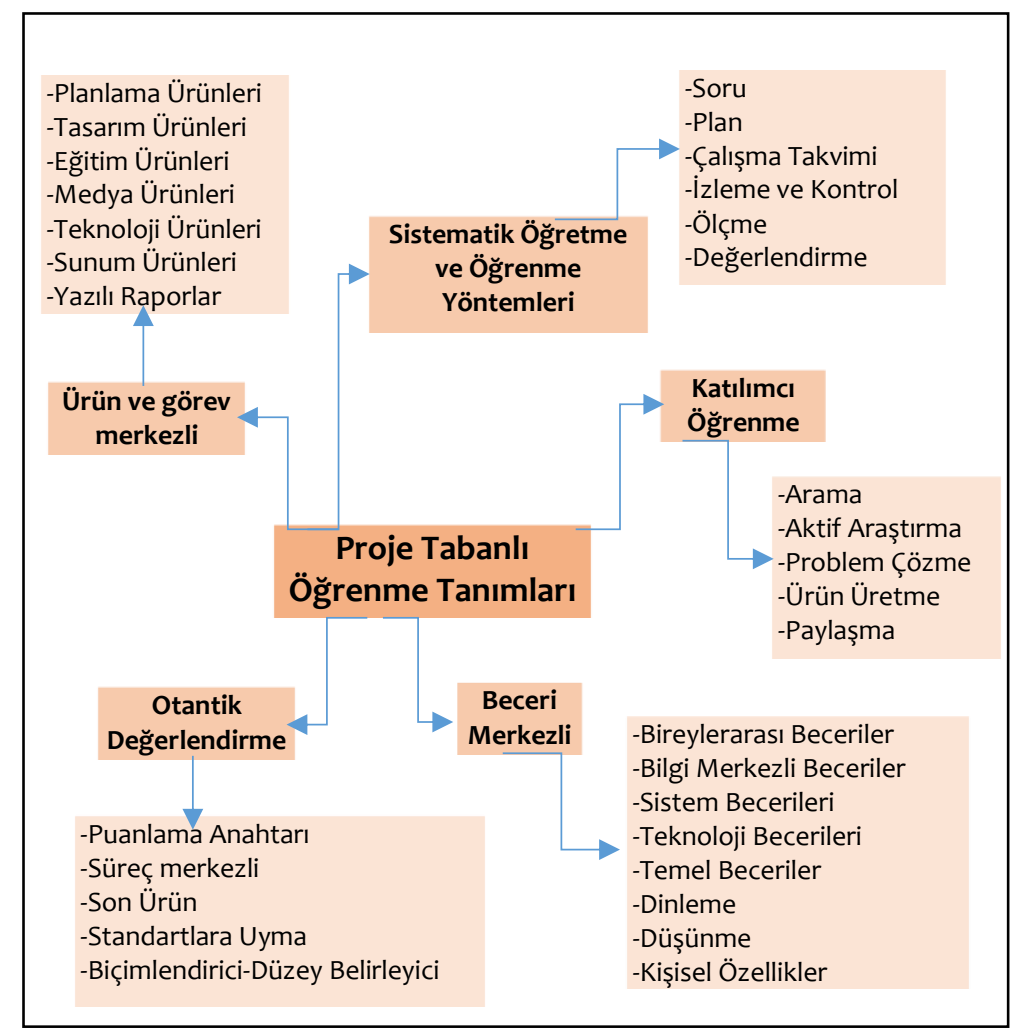

Şekil 1. Proje Tabanlı Öğrenmeye Yönelik Tanımların Sınıflandırılması (ETDME, 2006: 5)

Şekil 1' de görülen araştırma, planlama, izleme-kontrol, çalışma takvimi, ürün, süreç, beceriler, sistem, rapor vb. kavramlar proje tabanlı öğrenmenin olduğu kadar proje yönetiminin de temel unsurlarındandır. Temel kavramların ortak olması proje tabanlı öğrenme ile proje yönetiminin birbirleri ile benzer yanlarının olduğunu göstermektedir (Hutchison, 2015; P21 ve PMI-EF, 2014). Öğretmenler ve öğrenciler proje tabanlı öğrenme esnasında aslında proje yönetiminin de kapsama alanına girmektedir. Ancak proje tabanlı öğrenme uygulamalarında proje yönetimi bilgi alanlarının tümüyle dikkate alınmadığı söylenebilir.

Proje yönetimi ile proje tabanlı öğrenmenin uygun bir şekilde entegre edilmesi ile bu sürecin çok daha profesyonel bir şekilde çalışması sağlanabilmektedir (Fioravanti ve arkadaşları, 2018; P21, 2015, Amaral ve arkadaşları, 2015, De Los Rios ve arkadaşları, 2015; Hutchison, 2015; Musa ve arkadaşları, 2011). Proje tabanlı öğrenme sürecinde kapsam, maliyet, zaman, iletişim, kalite, tedarik, insan kaynakları, risk, paydaşlar ve entegrasyon anlamında oluşabilecek sıkıntılar da bu sayede minimize edilebilmektedir. $\mathrm{Bu}$ sayede alanyazında belirtilen projelerin tamamlanmasına yönelik yaşanan sorunlar azaltılabilecek ve üretilen projelerin daha yüksek bir başarı oranı ile tamamlanması sağlanabilecektir. Yapılan bir araştırmada, gerçekleştirilen entegrasyon sonucunda öğrencilerin proje tabanlı öğrenme sürecine kolay uyum sağladığı, adım adım projelerini hazırladıkları ve projelerini yeterli bir şekilde yönetebildikleri görülmüştür (Uysal ve Lepcha, 2016; P21 ve PMI-EF, 2014). Duruhan ve Şan (2017: 387) tarafından yapılan araştırmada adım adım ilerlemenin projeyi başarıya 
taşıyan bir faktör olduğu belirlenmiştir. Bu doğrultuda, proje yönetimi konusunda deneyimli olan öğretmenler, proje yönetimi bilgi alanlarını ile proje tabanlı öğrenme arasında gerekli entegrasyonu gerçekleştirmelidir. Böyle bir entegrasyonun sağlanabilmesi için, proje yönetimi bilgi alanlarının neler olduğu, ne anlama geldiği ve proje tabanlı öğrenme sürecine nasıl uygulanabileceğine yönelik bilgi ve deneyime sahip olunması gerektiği söylenebilir.

\section{Proje Yönetimi Bilgi alanları Nelerdir ve Bilgi Alanları Nasıl Tanımlanmaktadır?}

Alan uzmanları tarafindan proje yönetimi bilgi alanları; kapsam, iletişim, bütçe, zaman, insan kaynakları, tedarik, risk, kalite, paydaş ve entegrasyon yönetimi olarak belirtilmektedir (PMI, 2013). Bilgi alanlarına yönelik tanımlar aşağıda verilmiştir.

\subsection{Kapsam Yönetimi}

Proje kapsam yönetimi, projeyi başarıyla tamamlamak amacıyla, projenin sadece gerekli çalışmaları içermesini sağlamaktır (PMI-TR, 2009: 103). Tıpk1 araştırma konusunda olduğu gibi proje konusunda da bir sınırlamanın yapılarak çerçevesinin net bir şekilde belirlenmesi gerekmektedir (Karasar, 2006). Bu sayede daha net ve belirli bir alanda çalışma yapılabilmekte ve proje amaçlarına daha kolay ulaşılabilmektedir. Kapsam yönetiminde projenin başından sonuna kadar yapılacak işlere yönelik bir iş listesi hazırlanmaktadır. Bu iş listesi proje yönetimi için stratejik bir değer taşımakta ve diğer alanlar için de bir girdi olarak kabul edilmektedir.

\section{2.İletişim Yönetimi}

Proje bilgilerinin zamanında ve uygun şekilde üretilmesi, toplanması, dağıtılması, saklanması, erişilmesi ve gerektiğinde yeniden düzenlenebilmesi için gerekli süreçleri içermektedir (PMI-TR, 2009). Günümüz teknolojilerinin geldiği son nokta bilgi ve iletişim teknolojileri olarak isimlendirilmiştir. Buradan bilgi kadar iletişimin de ne kadar önemli görüldüğü anlaşılmaktadır. Çünkü bilginin üretilmesi, paylaşılması, yaygınlaştırılması, depolanması aslında gerçekleşen bir iletişim sürecinin dijital ortamlara aktarılmasıdır. Proje Yöneticileri işlerinde vakitlerinin yaklaşık olarak \%90'ını iletişsime ayırmaktadır (Luthra ve Dahiya, 2015; Watt, 2014; Rajkumar, 2010; Čulo ve Skendrović, 2010). Bu açıklama, proje yöneticileri, proje koordinatörü, proje üyeleri ve paydaşlar arasında gerçekleştirilen iletişim yönetiminin ne kadar stratejik olduğunu göstermektedir. İletişim becerileri çalışma ortamlarında da en çok gereksinim duyulan özelliklerden biri olduğu için iş ilanlarında da sürekli olarak aranmaktadır. Proje yönetimi sürecinde paydaşlar arasındaki iletişim süreci ne kadar açık, net ve hızlı olursa projeyi yönelik bilgi akışı da o kadar kolay olacak ve projede işler zamanında tamamlanabilmektedir. Basit bir iletişim hatasından dolayı projede büyük zararlar ortaya çıkabilmektedir.

\subsection{Zaman Yönetimi}

Projenin zamanında tamamlanabilmesi için gerekli işlem ve süreçlerden oluşmaktadır (PMI-TR, 2009). Her projenin kendine has başlama ve bitiş tarihleri vardır. Bu aradaki sürecin uzaması veya 
kısalması kapsam, bütçe veya kalite açısından bir takım olumsuz sonuçlar doğurabilmektedir. $\mathrm{Bu}$ yüzden proje ekibi en uygun çalışma takvimini hazırlamaktadır. Proje ekibi zaman yönetimine kapsam yönetiminde hazırlanan iş listesi ile başlamaktadır. İş listesinde yer alan işler eksiksiz, doğru ve sıralı bir şekilde tanımlanmaktadır. Proje uygulama sürecinde sonradan çıkacak bir iş projenin istenen zamanda bitmesini zorlaştırmaktadır.

Çalışma takviminde yer alan işler için proje ekibi tarafından doğru bir tamamlanma süresi belirlenmektedir. Gerekirse konu uzmanları ile görüsserek işin tamamlanma süresine yönelik doğru bir bilgi edinilmelidir. Aksi halde iş tahmin edilen sürede tamamlanmayabilmektedir. Bu şekilde proje ekibi tarafından çalışma takvimine son hali verilmekte ve projenin en başından itibaren işlerin çalışma takvimine uygun şekilde tamamlanması kontrol altına alınmaktadır.

\section{4.İnsan Kaynakları Yönetimi}

İnsan Kaynakları Yönetimi, proje ekibinin organize edilmesine, yönetilmesine ve yönlendirilmesine yönelik süreçleri içermektedir (PMI-TR, 2009). Projede belirlenen iş tanımlarını başarı ile tamamlayacak üyelere ihtiyaç duyulmaktadır. İşin büyüklüğüne, ağırlığına göre bu bir tek kişi olabildiği gibi bir çalışma grubu da olabilmektedir. Projelerde zaman zaman bazı işler proje ekibi dışında, hizmet alımı ile farklı firma ya da işletmelere de yaptırılabilmektedir. İnsan Kaynakları projeye etkili katkılar yapabilecek kişilerin projeye alınmasından, proje ekibinin geliştirilmesinden, motivasyonundan da sorumludur. Proje çıktıları ile sağlanabilecek istihdam firsatları için de çalışmalar yapmaktadır. İnsan Kaynakları proje işlerine uygun uzmanların belirlenmesini sağlayarak verimli bir çalışma ortamının kurulmasına ve bu sayede proje çıktılarının istenilen ölçütlerde üretilmesine büyük katkı sağlamaktadır.

\subsection{Bütçe Yönetimi}

Projenin onaylanan bütçe çerçevesinde tamamlanabilmesi için maliyetlerin tahminine, bütçelenmesine ve kontrolüne yönelik süreçleri içerir (PMI-TR: 165). Projelerde personel giderleri, ekipman ve malzeme giderleri, hizmet satın alma giderleri vb. gider kalemleri bulunmaktadır. Proje ekibi bu giderlerin maliyet hesabını proje kapsam zaman ve kalite yönetimi açısından dikkate alarak sahip olduğu bütçeye uygun bir şekilde yapmaktadır. Gereksiz, amacına uygun olmayan maliyetler proje bütçesinin aşılmasına ve bu yüzden projede bütçe kaynaklı bir takım sorunların ortaya çıkmasına neden olabilmektedir. Proje ekibi tüm bu gider kalemlerini düşünüp, gerekli piyasa araştırmalarını yaparak uygun maliyetleri belirler ve proje bütçesini hazırlamakta ve proje süresince azami ölçüde bu maliyetler doğrultusunda harcama yapmaktadır.

\subsection{Tedarik Yönetimi}

Gerekli ürünleri, hizmetleri ya da sonuçları proje ekibi dışından satın almak ya da elde etmek için gereken süreçleri kapsamaktadır (PMI-TR, 2009: 313). Proje paydaşları proje işlerinin gerçekleşebilmesi için gerekli araç ve gereçleri kendileri temin edebiliyorlarsa dışarıdan bir araç-gereç, 
malzeme, hizmet alımı yapmaya ihtiyaç duyulmamaktadır. Böylece bütçeden gereksiz harcamalar yapılmamaktadır. Ancak proje ekibi ve paydaşlarının karşılayamayacağı durumlarda proje kapsamında gerekli olan araç-gereç, malzeme, hizmet dışarıdan temin edilmektedir. Proje ekibi tedarik edilmesi gereken şeylerin bir listesini hazırlayıp farklı firmalardan özellik, ücret vb. konularda bilgiler alarak en uygun araç-gereç, malzeme veya hizmeti tedarik etmeye çalışmaktadır.

\subsection{Risk Yönetimi}

Risk, belirsiz ve tehlikeli bir durumu ifade etmektedir. Bir projede risk yönetimi, risklerin planlanması, belirlenmesi, analizi, yanıtların planlanması, uygulanması, izlenmesi ve kontrol edilmesi süreçlerini içermektedir (PMI-TR, 2009: 273). Projelerde iş listesi oluştururken proje ekibi belirsiz ve tehlike oluşturabilecek durumları da dikkate almak durumundadır. Risk olarak tanımlanan bu durumlar en doğru şekilde tespit edilmeye ve risklere karşı doğru önlemler alınmaya çalışılmaktadır. Her bir riskin projeye vereceği olası zararlar düşünülmekte ve riskin ortaya çıkarak projeye zarar vermesi engellenmeye çalışılmaktadır. Risk yönetiminin çok dikkate alınmadığı Titanik Faciası, konunun ne kadar önemli olduğunun açık bir örneğidir.

\subsection{Kalite Yönetimi}

Kalite amaçlara uygunluk, ölçütlerin karşılanması, sağlamlık, belirli standartlara sahip olma, bu standartların üzerine çıkma ve sürekli gelişim anlamlarında kullanılabilmektedir. Projede kalite ise en basit anlamda projeyi ortaya çıkaran ihtiyacın en etkili şekilde karşılanması ve proje çıktılarının istenilen ölçütlerde elde edilebilmesi olarak tanımlanabilir. Projede kalite yönetimi ise projeyi gerçekleştiren organizasyonun, projenin yapılma amacı olan ihtiyaçları karşılamasına yönelik kalite politikalarını, hedeflerini ve sorumluluklarını belirleyen süreçlerin ve aktivitelerin yönetimidir (PMI-TR, 2009: 189).

Proje ekibi proje çıtı veya ürünlerinin istenilen özellik ve standartlarda olabilmesi ise kalite planı hazırlamakta, kalite güvence çalışmaları yapmakta ve en son olarak kalite kontrol işlemleri uygulamaktadır. Kalite planında ürünlerin sahip olması gereken özellik ve ölçütler yer almaktadır. Proje ekibi uygulamada kalite planını dikkate alıp, kalite güvence standartlarına uygun işlemler yaptığında istediği çıktı veya ürünleri elde edebilmektedir. Son olarak da kalite kontrol işlemi yaparak hatalı, istenmeyen çıktı veya ürünleri ayırarak sadece istediği kalitedeki çıktı veya ürünleri kullanmaktadır. Şirketler arasında küresel bir yarışın olduğu günümüzde kalite ciddi anlamda önem kazanmıştır. Bilişim şirketlerinin, bilgisayarlar ve cep telefonlarının hızlı ve sürekli olarak özelliklerini geliştirerek kalitesini sürekli olarak yükseltmesi projelerde kalite yönetimin önemine açıça göstermektedir.

\subsection{Paydaş Yönetimi}

Projeler kapsamına, karmaşıklık derecesine, teknoloji seviyesine, risk seviyesine ve proje süresine göre A, B, C ve D gibi bir takım sınıflara ayrılabilmektedir (Suvacı, 2013: 6). Belirtilen özellikler ne kadar yüksek olursa, proje ne kadar disiplinler arası olursa o kadar paydaş gerekebilmektedir. Paydaş; proje etkinlikleri için yer alan, proje sonuçlarını, süreçlerini etkileyen ve 
bunlardan etkilenen kişi, grup veya kurumdur. Proje içinde aktif olarak yer almasa da dişarıdan proje sonuçlarına pozitif veya negatif olarak ilgisi olabilecek, proje ürünlerine talebi olabilecek kişi, grup veya kurumlar da paydaş olarak değerlendirilmektedir (PMI, 2013).

Paydaşların her biri farklı bir disiplini ve görevi temsil edebilmektedir. Proje süresince paydaşlar arasında doğan farklı fikirler bazı sorunlara, uyuşmazlıklara neden olabilmektedir. Bu nedenle projede bir takım değişiklikler istenebilmektedir. Özellikle proje başladıktan sonra istenen böyle bir değişim, proje için ciddi bir risk olabilmekte maliyet, zaman ve kalite anlamında projenin zora girmesine neden olabilmektedir. Proje süresince paydaşların görevlerini zamanında, belirtilen bütçe ile ve istenen kalite ölçütlerinde yapabilmesi için doğru bir şekilde yönlendirilmeleri gerekmektedir. Uzmanlar bu bağlamda büyük ölçekli, yüksek özellikli projeleri dikkate alarak paydaş yönetimini proje yönetimi içine yeni bir bilgi alanı olarak kabul etmiştir. Paydaş yönetimi, proje süresince paydaşların beklentilerini ve projeye etkilerini analiz etmek ve paydaşların etkili bir şekilde projeye katılımını saplamak için uygun yönetim stratejileri geliştirmekle yükümlü olmak üzere, projeyi etkileyebilen veya projeden etkilenebilen kişi, grup veya kurumların belirlenmesini sağlayan süreçleri içermektedir (PMI, 2013). Paydaşlar, proje gereksinimlerine uygun olarak belirlenmekte ve proje yöneticisi veya koordinatörü tarafindan görevleri kendilerine bildirilmektedir. Yine çalışmaları proje yöneticisi veya proje koordinatörü tarafından kontrol edilmekte ve denetlenmektedir.

\subsection{Entegrasyon Yönetimi}

Proje yönetiminin en karmaşık ve zor olan alanı olduğu söylenebilir. Şekil 2'de Entegrasyon yönetiminin, proje yönetiminin neresinde olduğu, proje yönetimini nasıl etkilediği açık bir şekilde görülmektedir. Entegrasyon yönetimi, proje yöneticilerinin zaman içinde farklı proje deneyimleri ile kazanabilecekleri ciddi bir uzmanlık alanıdır. Çünkü entegrasyon yönetimi, tüm alanları ayrı ayrı bilmekle birlikte, uygulamada hepsini birden aynı anda düşünerek işe koşmayı gerektirmektedir. 


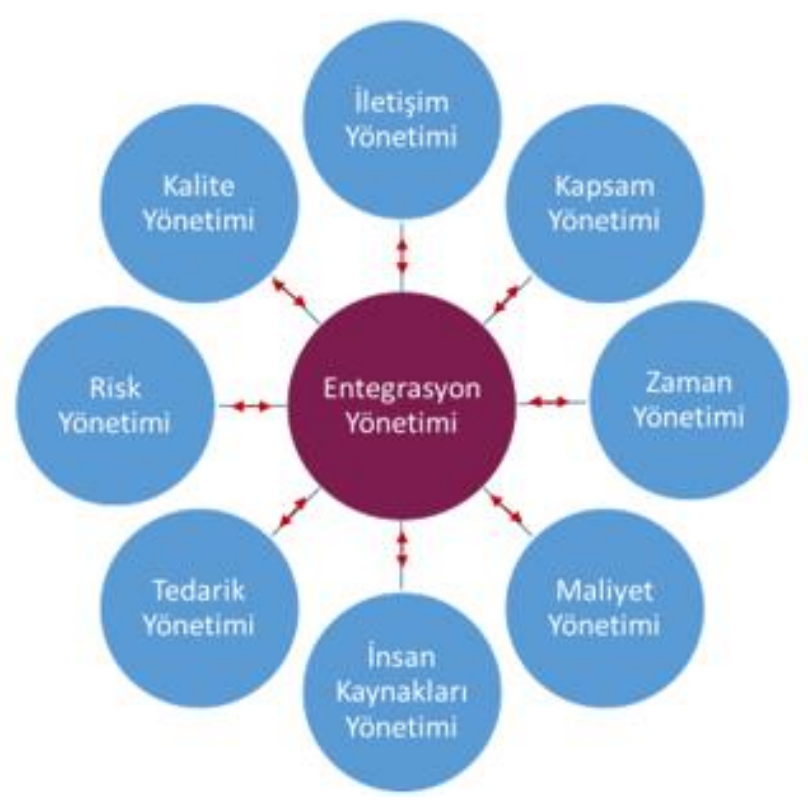

Şekil 2. Entegrasyon Yönetimi Bilgi Alanı

Proje sürecinde bilgi alanları çoğunlukla etkileşim içinde olmaktadır. Bu etkileşimlerin başarılı sonuçlar verebilmesi, entegrasyon yönetiminin ne kadar etkili bir şekilde yapıldığına bağlıdır. Entegrasyon yönetimi sayesinde diğer bilgi alanları birbirleriyle uyum içinde çalışabilmektedir. Aksi bir durumda bilgi alanları birbirini olumsuz etkileyebilmekte ve projenin kapsamında, zamanında ve bütçesinde bitmesi zorlaşabilmektedir.

Entegrasyon yönetimi en basit anlamda araba veya bisiklet kullanmaya benzetilebilir. Süreç içerisinde gözler yola bakıp etrafı kontrol ederken, eller direksiyon tutmakta, vites değiştirmekte, ayaklar gaza veya frene basmaktadır. Bu işlemlerin hepsi de yolun durumuna göre eş zamanlı olarak gerçekleştirilmektedir. Entegrasyon yönetiminde sistemi oluşturan her unsur dikkate alınmaktadır.

3.Proje yönetimi bilgi alanları dikkate alınarak bir proje geliştirilebilir mi? Proje yönetimi bilgi alanları ile özgün bir proje nasıl geliştirilebilir? Süreç içerisinde neler yapılmalıdır?

Proje yönetimi bilgi alanları tanımlandıktan sonra bilgi alanları ile özgün bir proje geliştirilmesi için aşağıdaki başlıklar altında örnek uygulamalar verilmektedir. Örnek uygulamalar 2. soruda açıklamaları yapılan proje yönetimi bilgi alanlarına bağlı olarak geliştirilmiştir. Özgün bir proje olarak E-Okuma Takvimi projesi ele alınmaktadır. E-Okuma Takvimi proje sürecinde yapılacak işler, kapsam yönetimi çerçevesinde yapılması gerektiği için proje geliştirme sürecine kapsam yönetimi ile başlamanın uygun olduğu ifade edilebilir.

\subsection{Kapsam Yönetimi Örnek Uygulama}

Eğitim Kurumları başta olmak üzere ilgili, gönüllü ve sorumlu tüm kurumlar okumaya yönelik seferberlik çağrısı yapmakta ve projeler ortaya koymaktadır. Bu konuda verilebilecek destekler toplum tarafından da oldukça değerli görülmektedir. Proje kapsamında gerekli ihtiyaç analizleri okul müdürleri, 
öğretmenler, aileler ve öğrenciler ile görüşülerek yapılmaktadır. Daha donanımlı bir toplum olmamı, ülkemizin küresel yarışlarda daha başarılı olabilmesi vatandaşlarımızın okuma alışkanlığı kazanması ile doğrudan ilgili olacağı söylenebilir. Bu bağlamda 21. yüzynl öğrenci özellikleri, bilgi ve iletişim teknolojilerinin sağlayabileceği kazanımlar ve maliyetler dikkate alınarak bir "E-Okuma Takvimi" projesi geliştirilmesi kararı alınmıştır. Okuma Takvimi ilkokul 4. sınıf öğrencilerine okuma alışkanlığı kazandırmayı amaçlayan bir projedir. Bir eğitim-öğretim yılı içinde öğrencilere okuma alışkanlığı kazandırılabileceği düşünülmektedir.

Bu bağlamda aşağıdaki gibi örnek bir iş listesi hazırlanmıştır:

1. E-Okuma Takvimi çalışma grubunun oluşturulması

2. E-Okuma Takvimi projesi iş planının yapılması

3. E-Okuma Takvimi projesi çalışma takviminin hazırlanması

4. E-Okuma Takvimi sayfaları içinde yer alacak bilgi gruplarının belirlenmesi (Önemli günler, önemli kişiler, kahramanlar, şiirler, destanlar, mektuplar, sözler, günün anlam ve önemine yönelik bilgilendirmeler, öğrenciler için değerlendirme sorusu/soruları vb.)

5. Takvim gününe uygun olacak şekilde, 1 aylık takvim sayfaları için içerik tasarımının yapılması (Sayfa uzunluğunu eklenecek olan içerik belirleyecektir. Çevrimiçi ortamda sayfa uzunluğu kısıtı olmaması proje için bir artı olarak düşünülebilir.)

6. Her bir takvim sayfasının son haline karar verilmesi için proje ekibi tarafından kontrol edilmesi ve E-Okuma Takviminin 1aylık bölümünün tamamlanması

7. E-Okuma Takviminin internet ortamına aktarılması ve etkileşimler için düzenlenmesi

8. Kalan 11 aylık E-Okuma Takvimi sayfa tasarımı için gönüllü ve istekli 11 okulun ve çalışma ekiplerinin belirlenmesi

9. Takvim gününe uygun olacak şekilde, takvim sayfaları için içerik tasarımının yapılarak 11 ay için E-Okuma Takviminin tasarım sürecinin tamamlanması

10. E-Okuma Takviminin tümünün internet ortamına aktarılması ve çevrimiçi etkileşim araçları eklenerek düzenlenmesi (E-Okuma Takvimi çevrimiçi öğrenme ortamında)

11. Okuma alışkanlıkları tutum ölçeğinin geliştirilerek proje öncesi verilerin toplanması

12. E-Okuma takvimi projesi hakkında öğrencilerin-ailelerin, öğretmenlerin bilgilendirilmesi

13. Öğrencilerin öğretmen ve ailelerinin gözetiminde okuma takvimini okumaya başlaması 
14. Her haftanın son günü öğrenciler arasında okuma takvim sayfalarına yönelik paylaşımların, değerlendirmelerin yapılması, sorulara sınıf öğretmeni modaratörlüğünde yanıtlar verilmesi

15. Sınıf Öğretmeninin aileleri ile birlikte öğrencilerin E-Okuma Takvimi sayfalarını okumalarını takip etmeleri, sorun tespiti durumunda ilgili öğrenciler ile özel olarak ilgilenmeleri ve aileleri ile irtibata geçmesi

16. Eğitim-öğretim yılı sonunda okuma alışkanlıkları tutum ölçeğine yönelik proje sonrası verilerin toplanmas1

17. Verilerin analiz edilerek proje sonuç raporunun yazılması ve sonuçların yaygınlaştırılması

\section{2.İletişim Yönetimi Örnek Uygulama}

Bünyesinde projeyi yönetecek olan kurum tarafından bir proje ekibi oluşturulur. Proje ekibi proje işleri hazırlanırken ya da tamamlanırken ilgili diğer proje paydaşları ile iletişime geçerek onları yapılan işe yönelik bilgilendirmekte ya da onlardan bilgi almaktadır. Kapsam yönetiminde belirlenen 1.Okuma Takvimi çalışma grubunun oluşturulması, 2.Okuma Takvimi projesi iş planının yapılması ve 3.Okuma Takvimi projesi çalışma takviminin hazırlanması vb. işler işbirliği içinde çalışmayı gerektirmektedir. Bu bağlamda birlikte çalışma günleri, toplantı saatleri belirlenerek ortak çalışmalar ilgili proje üyeleri ve paydaş temsilcileri ile birlikte yapılmaktadır. Hangi medya araçları ile iletişim kurulacağına proje yöneticisi veya proje koordinatörü tarafindan proje paydaşları ile birlikte karar verilmekte ve bu araçlar üzerinden projeye yönelik bilgi ve belgeler ilgili proje üyeleri ve paydaşlar ile paylaşılmaktadır. İş listesindeki her bir işin gidişatına yönelik bilgiler veriler, varsa sorunlar üzerinde durulmakta, aksayan yönler düzeltilmekte, sorunlar çözülerek işlerin zamanında ve uygun bir bütçe ile çözümlenmesi sağlanmaktadır. İş listesinde görevli ve sorumlu olan proje üyeleri ve paydaş kurum temsilcileri iş tamamlanıncaya kadar birbirleri ile iletişim içinde olup, gerekli durumlarda proje koordinatörünü bilgilendirmektedir. 


\subsection{Zaman Yönetimi Örnek Uygulama}

Proje ekibi Tablo 1'de görüldüğü E-Okuma Takvimi Projesi iş listesine uygun bir çalışma takvimi oluşturabilir:

Tablo 1: E-Okuma Takvimi Projesi Çalışma Takvimi

\begin{tabular}{|c|c|c|}
\hline Proje İş Listesi & $\begin{array}{l}\text { Tahmini Başlama } \\
\text { Bitirme Tarihi }\end{array}$ & Süresi \\
\hline 1. E-Okuma Takvimi çalışma grubunun oluşturulması & 7-14 Ocak 2019 & 1 Hafta \\
\hline 2. E-Okuma Takvimi projesi iş planının yapılması & 14-21 Ocak 2019 & 1 Hafta \\
\hline 3. E-Okuma Takvimi projesi çalışma takviminin hazırlanması & 14-21 Ocak 2019 & 1 Hafta \\
\hline $\begin{array}{l}\text { 4. E-Okuma Takvimi sayfaları içinde yer alacak bilgi gruplarının } \\
\text { belirlenmesi (Önemli günler, önemli kişiler, kahramanlar, } \\
\text { şiirler, destanlar, mektuplar, sözler, günün anlam ve önemine } \\
\text { yönelik bilgilendirmeler, öğrenciler için değerlendirme } \\
\text { sorusu/soruları vb.) }\end{array}$ & 21 Ocak -21 Mart 2019 & 2 Ay \\
\hline $\begin{array}{l}\text { 5. Takvim gününe uygun olacak şekilde, } 1 \text { aylık takvim sayfaları } \\
\text { için içerik tasarımının yapılması (Sayfa uzunluğunu eklenecek } \\
\text { olan içerik belirleyecektir. Çevrimiçi ortamda sayfa uzunluğu } \\
\text { kısıtı olmaması proje için bir artıdır.) }\end{array}$ & 21 Ocak -21 Mart 2019 & 2 Ay \\
\hline $\begin{array}{l}\text { 6. Her bir takvim sayfasının son haline karar verilebilmesi için } \\
\text { proje ekibi tarafından kontrol edilmesi ve Okuma Takviminin } \\
\text { tamamlanması ( } 1 \text { aylık örnek tasarım) }\end{array}$ & $\begin{array}{l}21 \text { Mart -28 Mart } \\
2019\end{array}$ & 1 Hafta \\
\hline $\begin{array}{l}\text { 7. E-Okuma Takviminin internet ortamına aktarılması ve } \\
\text { etkileşimler için düzenlenmesi }\end{array}$ & $01-07$ Nisan 2019 & 1 Hafta \\
\hline $\begin{array}{l}\text { 8. Kalan } 11 \text { aylık E-Okuma Takvimi sayfa tasarımı için gönüllü ve } \\
\text { istekli } 11 \text { okulun ve çalışma ekiplerinin belirlenmesi }\end{array}$ & $07-14$ Nisan 2019 & 1 Hafta \\
\hline $\begin{array}{l}\text { 9. Takvim gününe uygun olacak şekilde, takvim sayfaları için } \\
\text { içerik tasarımının yapılarak } 11 \text { ay için E-Okuma Takviminin } \\
\text { tasarım sürecinin tamamlanması (E-Okuma Takvimi kullanıma } \\
\text { hazır) }\end{array}$ & $\begin{array}{l}14 \text { Nisan - } 14 \text { Haziran } \\
2019\end{array}$ & 2 Ay \\
\hline $\begin{array}{l}\text { 10. E-Okuma Takviminin tümünün internet ortamına aktarılması } \\
\text { ve çevrimiçi etkileşim araçları eklenerek düzenlenmesi }\end{array}$ & $14-28$ Haziran 2019 & 2 Hafta \\
\hline $\begin{array}{l}\text { 11. Okuma alışkanlıkları tutum ölçeğinin geliştirilerek proje } \\
\text { öncesi verilerin toplanması }\end{array}$ & $\begin{array}{l}14 \text { Ocak - } 14 \text { Mayıs } \\
2019\end{array}$ & 4 Ay \\
\hline $\begin{array}{l}\text { 12. E-Okuma takvimi projesi hakkında öğrencilerin-ailelerin ve } \\
\text { öğretmenlerin bilgilendirilmesi }\end{array}$ & $\begin{array}{l}24 \text { Nisan - } 14 \text { Haziran } \\
2019 \\
\end{array}$ & 2 Hafta \\
\hline $\begin{array}{l}\text { 13. Öğrencilerin ailelerinin ve öğretmenlerinin gözetiminde E- } \\
\text { Okuma Takvimini okumaya başlaması }\end{array}$ & $\begin{array}{l}\text { Eylül } 2019 \text { - Haziran } \\
2020\end{array}$ & 9 Ay \\
\hline $\begin{array}{l}\text { 14. Her haftanın son günü öğrenciler arasında okuma takvim } \\
\text { sayfalarına yönelik paylaşımların, değerlendirmelerin } \\
\text { yapılması, sorulara sınıf öğretmeni modaratörlüğünde } \\
\text { yanıtlar verilmesi vb. }\end{array}$ & $\begin{array}{l}\text { Eylül } 2019 \text { - Haziran } \\
2020\end{array}$ & 9 Ay \\
\hline $\begin{array}{l}\text { 15. Sınıf Öğretmeninin aileleri ile birlikte öğrencilerin E-Okuma } \\
\text { Takvimi sayfalarını okumalarını takip etmeleri, sorun tespiti } \\
\text { durumunda ilgili öğrenciler ile özel olarak ilgilenmeleri ve } \\
\text { aileleri ile irtibata geçmesi }\end{array}$ & $\begin{array}{l}\text { Eylül } 2019 \text { - Haziran } \\
2020\end{array}$ & 9 Ay \\
\hline $\begin{array}{l}\text { 16. Eğitim-öğretim yılı sonunda okuma alışkanlıkları tutum } \\
\text { ölçeğine yönelik proje sonrası verilerin toplanması }\end{array}$ & Haziran 2020 & $1 \mathrm{Ay}$ \\
\hline $\begin{array}{l}\text { 17. Verilerin analiz edilerek proje sonuç raporunun yazılması ve } \\
\text { sonuçların yaygınlaştırılması }\end{array}$ & Temmuz-Aralık 2020 & 5 Ay \\
\hline & TOPLAM & $24 \mathrm{Ay}$ \\
\hline
\end{tabular}




\section{4.İnsan Kaynakları Yönetimi Örnek Uygulama}

Proje fikri sahibi tarafından güvenilen bir alan uzmanına danışılması ile birlikte projenin insan kaynakları oluşmaya başlamaktadır. Alan uzmanı, proje fikri sahibi ile birlikte proje ekibini ve diğer paydaşları belirleyerek proje bağlamında insan kaynaklarını oluşturmaktadır. Proje ekibinde araştırma uzmanları, içerik geliştirerek sayfa tasarımı yapacak gönüllü öğretmenler, takvim sayfalarını internet ortamına aktaran ve görseller konusunda yardımcı olan bilişim formatörleri görev yapmaktadır. EOkuma Takvimi projesi bir Fakülte ve İl Milli Eğitim Müdürlüğü tarafından desteklenmektedir.

E-Okuma Takvimi projesi bünyesinde proje ekibi tarafından iş listesi oluşturulmuş ve iş planı hazırlanarak her bir iş için görevli ve sorumlu kişiler belirlenmiştir. Proje ekibi 4.Okuma Takvimi sayfaları içinde yer alacak bilgi gruplarının belirlenmesi (önemli günler, önemli kişiler, kahramanlar, şiirler, destanlar, mektuplar, sözler, günün anlam ve önemine yönelik bilgilendirmeler, öğrenciler için değerlendirme sorusu/soruları vb.) üzerinde çalışmalar yaparak belirledikleri örnek bir ayın içerik tasarımını yapmaktadır. İçerik tasarımı için proje ekibi içinde istekli ve gönüllü olarak projeye katılan 10 öğretmen de görev yapmaktadır. İçerik tasarımında kullanılacak resim, grafik, yerleşim düzeni vb. konularda destek olması nedeniyle 3 bilişim formatörü de projeye teknik destek vermektedir. Proje ekibi işbölümü yaparak, her öğretmen tarafından 3 günlük sayfa tasarımı yapılmasına ve her bir bilişim formatörünün de 10 günlük sayfa tasarımının dijital ortama aktarmasına karar vermiştir. Sayfa olarak internet sayfası kastedildiği için sayfa uzunluğu konusunda bir sorun yaşanmayacak ancak uzunluk eklenmesi yerinde ve anlamlı görülen içerik ile sınırlandırılmaktadır. Proje ekibi her bir takvim sayfasının son haline karar verebilmek için son bir kalite kontrol işlemi yapmakta ve gerekli düzenlemelerin ardından 1 aylık E-Okuma Takvimi tasarımı ilgili etkileşim öğeleri ile birlikte internet ortamına aktarmaktadır. Etkileşim öğeleri, sayfayı tasarlayan öğretmenler ve ilgili bilişim formatörü tarafından hazırlanmaktadır.

Proje ekibi kalan 11 ayın sayfa tasarımları için paydaş 11 okul ile işbirliği yapmaktadır. Bu okullarda kurulan paydaş proje ekipleri tarafından benzer çalışmalar yapılmakta ve tamamlanan 1 aylık sayfa tasarımları proje ekibine teslim edilmektedir. Proje ekibi, paydaş okulların proje ekipleri tarafından hazırlanan sayfa tasarımları arasında bütünlügü korumak amacıyla son bir kontrol ve düzenleme yapmakta ve tüm okuma takvimi sayfalarının etkileşim öğeleri ile birlikte bilişim formatörleri tarafından internet ortamına yüklenmesini sağlamaktadır. Öğrencilerin E-Okuma Takvimini okuma durumları Evet-Hayır, Doğru-Yanlış, Açık Uçlu vb. sorulara verdikleri yanıtlardan sistem üzerinden otomatik olarak takip edilebilmektedir.

Projede görev yapan araştırmacılar E-Okuma Tutum Ölçeğini geliştirmekte, proje uygulama öncesinde ve sonrasında gerekli verileri toplamakta ve ilgili istatistiksel hesaplamaları yaparak proje sonuç raporunu yazmaktadır. 


\subsection{Bütçe Yönetimi Örnek Uygulama}

E-Okuma Takvimi projesi bir sosyal sorumluluk projesi olduğundan kurumlar kendi bütçelerinden harcama yapmaktadır. Proje bütçesinde personel giderlerine yönelik bir gider bulunmamaktadır. Proje ekibi tarafından belirlenen gider kalemleri, araştırmacıların araştırma sürecinde yapacağı harcamalar ve "ayın okuyucusu" seçilen öğrencilere verilecek hediye kitapların ücreti olarak belirlenmiştir. Araştırmacıların araştırma sürecinde yapacağı toplam harcama 5.000TL ve 12 Okulda proje süresince her ay ayın okuyucusuna verilecek kitapların ücreti $2.500 \mathrm{TL}$ olarak toplam bütçe bedeli 7.500TL olarak belirlenmiştir. E-Okuma Takvimi projesi bir sosyal sorumluluk projesi olmasaydı çok daha farklı bütçe giderleri olacağı ve çok daha büyük bir bütçenin ortaya çıkacağı ifade edilebilir.

\subsection{Tedarik Yönetimi Örnek Uygulama}

E-Okuma Takvimi projesi bir Fakülte ve İl Milli Eğitim Müdürlüğü tarafından desteklenen bir projedir. Bu bağlamda proje için gerekli olan araç-gereç, malzeme ve insan kaynaklarının tamamına yakını ilgili kurumlardan karşılanmaktadır. Proje süresince her ay 12 okulda ayın okuyucusuna bir kitap hediye edilmektedir. İnternet ortamında okuma süresi 8 ay sürmesi planlanan E-Okuma Takvimi projesi bünyesinde 12 Okulda 96 kitap hediye olarak verilmektedir. 96 kitap tedarik edebilmek için $2.500 \mathrm{TL}$ bütçe ayrılmıştır. Hediye edilecek bu kitaplar, proje ekibi tarafından belirlenerek uygun fiyat alabildikleri bir yayın evinden sağlanmaktadır.

\subsection{Risk Yönetimi Örnek Uygulama}

E-Okuma Takvimi projesinde en riskli durum sayfaların tasarımı olarak görülmektedir. EOkuma Takvimi projesinde en fazla çaba sayfaların oluşturulması için gösterilmektedir. 365 sayfanın etkili verimli ve çekici bir şekilde geliştirilebilmesi ciddi anlamda bir risk taşımaktadır. Sayfa üretimini daha kolay bir hale getirebilmek için Proje Koordinatörü önderliğinde 10 uzman öğretmen ve 3 bilişim formatörü işbirliği yaparak 1 aylık sayfa tasarımı yapılmaktadır. Proje ekibinin 1 aylık sayfa tasarımını son kez kontrol etmesinin ardından E-Okuma Takviminin 1 aylık bölümü tamamlanmakta ve gerekli çevrimiçi etkileşim öğeleri ile birlikte internet ortamından yayınlanmaktadır. Projenin daha erken zamanda tamamlanabilmesi için tamamlanan ve kontrol edilen 1 aylık örnek sayfa tasarımları dikkate alınarak 11 okulda benzer bir çalışma yapılmaktadır. Çalışmada sayfalar arasındaki bütünlüğünün korunabilmesi için proje ekibi tarafından değerlendirmeler yapılmakta ve öneriler sunulmaktadır. 365 sayfalık bir E-Okuma Takvimi içeriği bu şekilde hazırlanmaktadır. Öğrencilerin ve ailelerin uygulama esnasında her hangi bir sorunla karşı karşıya gelmemeleri için okullarda proje ekibi tarafından E-Okuma Takvimi projesine yönelik bilgilendirmeler ve örnek uygulamalar yapılmaktadır. İnternet ortamında sorun yaşayan öğrencilere ise E-Okuma Takvimi basılı olarak verilebilmektedir. 


\subsection{Kalite Yönetimi Örnek Uygulama}

E-Okuma Takvimi projesinde yeterli sayıda insan kaynağı görev yapmaktadır. Daha kaliteli bir sayfa tasarımı için proje üyelerinin iş yükü minimize edilmektedir. Takvim sayfaları arasındaki bütünlüğü korumak amacıyla sayfalarda hangi türde içeriklerin olması gerektiğine ve gerekli etkileşim araçlarına proje ekibi tarafından karar verilmektedir. Sayfa tasarımlarında, yayın öncesi proje ekibi tarafından son bir kalite kontrol çalışması da yapılmaktadır. İçerik olarak önemli günler, önemli kişiler, kahramanlar, şiirler, destanlar, mektuplar, sözler, günün anlam ve önemine yönelik bilgilendirmeler, öğrenciler için doğru-yanlış, evet-hayır soruları, açık uçlu değerlendirme sorusu/soruları vb. bilgi ve soru alanı olmasına karar verilmiştir. Amaç öğrencilerin sürece aktif olarak katılmalarını sağlamaktır. Soru-Cevap bölümleri aktif katılımın bir göstergesi olarak kabul edilmektedir.

Sınıf Öğretmenleri öğrencilerin verdikleri yanıtları internet sayfasından görebilmektedir. Haftanın son gününde o hafta yapılan okumalar üzerine öğretmen moderatörlüğünde sınıfça bir değerlendirme yapılmaktadır. Daha deneyimli oldukları için sayfa tasarımına katılan aynı zamanda proje üyesi olan öğretmenlerin bu uygulama sürecine katılmalarına öncelik verilmektedir. Moderatör denetiminde yapılan sınıf değerlendirmeleri sayede öğrenilen bilgiler daha kalıcı olabilmektedir. Sınıf öğretmeni internet üzerinden öğrencilerin E-Okuma Takvimi okumalarını basit bir şekilde takip edebilmektedir. E-Okuma Takvimine internet üzerinden ve ayrıca mobil bir uygulama ile tablet ve cep telefonlarından da ulaşılabilmektedir. Aileler de bu mobil uygulamadan E-Okuma Takvimine ulaşabilmekte ve çocuklarının aktif katılım durumunu takip edebilmektedir. Öğrenciler sayfa tasarımlarını oylayarak sayfa tasarımına yönelik görüş yazabilmektedir. Tüm bu çalışmalar kalite yönetimi bağlamında yapılmaktadır.

\subsection{Paydaş Yönetimi Örnek Uygulama}

E-Okuma Takvimi projesi kapsamında; projeyi yönetebilecek bir proje yöneticisine, proje işlerinin gerçekleştirilmesinden sorumlu bir proje koordinatörüne, içerik tasarımı yapan öğretmenlere, tasarlanan içerikleri internet ortamına aktaran ve gerekli etkileşim öğelerini internet ortamında sayfalara aktararak E- Okuma Takviminin internet ortamında doğru bir şekilde çalışmasını sağlayan bilişim formatörlerine ihtiyaç duyulmaktadır.

Projeye aktif olarak katılan, takvim sayfalarını internet üzerinden okuyan, sorulara yanıt veren öğrenciler ve sınıflarında öğrenciler ile okuma takvimindeki içeriklere yönelik haftalık değerlendirmeler yapan öğretmenler ve çocuklarının takvim sayfalarını okuma durumlarını takip eden aileler de E-Okuma Takvimi projesinin paydaşları arasındadır.

Araştırma için okuma alışkanlıkları tutum ölçeğini geliştiren, gerekli verileri toplayan, proje raporunu yazan araştırmacılar da projenin paydaşlarındandır. Ayın okuru seçilen öğrencilere hediye edilen kitapların alındığı yayın evi de yine bir paydaş olarak kabul edilebilir. Proje paydaşları arasında; proje yöneticisi ve proje koordinatörü kişi anlamda, okullarda aylık takvim sayfası tasarımı yapacak 
proje ekipleri grup anlamında ve projeyi destekleyecek İl Milli Eğitim Müdürlüğü ve Fakülte ile projenin gerçekleştirileceği okullar ve kitapların alınacağı yayınevleri kurumsal anlamda projenin paydaşlarıdırlar.

Proje yöneticisi proje için gerekli izinleri alıp, gerekli bütçeyi hazırladıktan sonra proje koordinatörünün denetiminde proje işleri yapılmaya başlanmaktadır. Proje koordinatörü yapılan işe göre diğer paydaşlar ile iletişime geçmekte ve işlerin istendiği şekli ile zamanında ve bütçesinde tamamlanmasını sağlamaktadır. Paydaşlar, proje iş listesinde kendilerine verilen görevlerden sorumlu olmaktadir.

\subsection{Entegrasyon Yönetimi Örnek Uygulama}

E-Okuma Takvimi projesi bünyesinde istenen proje ürünlerinin elde edilebilmesi için entegrasyon yönetimi konusunda gereken hassasiyet gösterilmiştir. Özellikle Kapsam Yönetiminde açıklanmış olan İş Listesinin oluşturulması sürecinde diğer bilgi alanları ile olan etkileşimler dikkate alınmıştır. Örneğin 1 aylık örnek sayfa tasarımı tamamlandıktan sonra 11 okul aynı anda bu örnek tasarımları model alarak kendi tasarımlarını oluşturmaktadır. $\mathrm{Bu}$ sayede takvim sayfalarının tamamlanması sürecinde çok ciddi bir zaman kazanılmaktadır. E-Okuma Takvimi projesi uygulama sürecinde öğretmenlerin ve ailelerin, öğrencilerin okumalarını takip edebilmeleri için sağlanan altyapı da yine bu entegrasyon yönetiminin bir ürünü olarak değerlendirilmektedir. Araştırmacıların proje için gerekli verileri de E-Okuma Takvimi projesi internet sitesinden toplayabilmeleri de entegrasyon yönetiminin başka bir artısı olarak görülmektedir.

\section{Sonuç Ve Öneriler}

Projelerin kapsamında, zamanında, maliyetinde ve istenilen kalite ölçütlerinde tamamlanmasında ciddi sorunlar olduğu bildirilmektedir (Pinto, 2010; Standish Group, 2014). Alanyazında bu sorunların özellikle iletişim, kapsam, planlama, risk, insan kaynakları ve tedarik gibi doğrudan proje yönetimi bilgi alanları ile ilgili olduğu gösterilmektedir (Budak, 2012; Suvac1, 2013). Ayrıca her üç projeden birinin proje yönetim bilgi alanlarına bağlı olarak kazanılan proje yönetimi becerilerinin yetersizliği nedeniyle başarısızlığa uğradığı belirtilmektedir (Çankaya, 2006: 51-52;). Bu gerçek göz önünde bulundurularak bu araştırmada proje yönetimi ve proje yönetimi bilgi alanları olan kapsam, iletişim, bütçe, zaman, insan kaynakları, tedarik, risk, kalite ve entegrasyon yönetimi tanıtılmış ve uygulanmasına yönelik bilgiler verilmiştir.

Güçlü öğrenme çıktıları ve beceri kazanımları nedeniyle proje tabanlı öğrenme ülkemizde daha fazla tercih edilen yöntemlerden biri haline gelmiştir. Öğrencilerin proje tabanlı öğrenme uygulamalarında aslında dolaylı olarak proje yönetimi yaptığı söylenebilir. Araştırma bağlamında, alanyazın bilgilerine dayalı olarak proje yönetimi ve proje yönetimi bilgi alanlarının bilinmesi ile proje tabanlı öğrenmenin daha etkili olarak gerçekleştirilebileceği belirtilmektedir (Fioravanti ve arkadaşları, 
2018; De Los Rios ve arkadaşları, 2015; Hutchison, 2015; Amaral ve arkadaşları, 2015; P21, 2015; Morgan ve arkadaşları, 2013; Byrne ve arkadaşları, 2008; Mergendoller ve arkadaşları, 2006).

Araştırma sonucunda proje yönetimi bilgi alanları ile özgün bir projenin adım adım geliştirilebildiği görülmektedir. Duruhan ve Şan (2017: 387) tarafından yapılan araştırmada projeyi başarıya taşıyan faktörler "düşünerek planlı çalışma" ve "adım adım ilerleme" olarak bulunmuştur. Bu sonuç doğrultusunda proje yönetiminin on farklı bilgi alanı dikkate alınarak proje tabanlı öğrenmenin daha profesyonel bir bakış açısı ile başarılı bir şekilde uygulanabileceği belirtilebilir.

Araştırma konusuna yönelik aşağıdaki öneriler sunulabilir:

- Proje tabanlı öğrenme uygulamalarının daha profesyonel bir şekilde gerçekleştirilebilmesi için öğretmenler ve öğrenciler proje yönetimi ve proje yönetimi bilgi alanlarına yönelik bilgilendirilebilir.

- Alan uzmanları tarafından proje yönetimi bilgi alanları dikkate alınarak farklı disiplinlerde projeler geliştirilerek, geliştirme süreç ve işlemleri alanyazında paylaşılabilir.

- $\quad$ Öğreticiler ve öğrenenler başta olmak üzere proje tabanlı çalışan kişiler, araştırma kapsamında geliştirilen proje süreci dikkate alınarak özgün yeni projelerin ortaya çıkmasını sağlayabilir. 


\section{Kaynaklar}

Amaral, A., Alberto, J., Paulo, G., Aurélio, H. (2015). Creating a project-based learning environment to improve project management skills of graduate students. Journal of Problem Based Learning in Higher Education, 3(2), $120-130$.

Avcı, E., Su Özenir, Ö. ve Yücel, E. (2016). Students' experiences during Tübitak secondary education students' research projects competition and its contribution to their university life*. Uşak Üniversitesi Sosyal Bilimler Dergisi, 9(3), 1-21.

Ay, Ş. (2013). Öğretmen adaylarının proje tabanlı öğrenme ve geleneksel öğretime ilişkin görüşleri. Hacettepe Üniversitesi Eğitim Fakültesi Dergisi, 28(1), 53-67.

Ayas, C., Çeken, R., Eș, H. ve Taştan, B. (2013). "Bu benim eserim” fen bilimleri projelerinde vatandaşlık eğimi açısından sosyal sorumluluk ve vatandaşlık bilinci. Adryaman Üniversitesi Sosyal Bilimler Enstitüsü Dergisi, (14), $1-19$.

Aydın, S., Atalay, T. D. ve Göksu, V. (2018). Project-based learning practices with secondary school students, International Online Journal of Educational Sciences, 10(3), 230-242.

Budak, F. (2012). Proje yönetimi eğitimi ders notları. İstanbul: FABE.

Byrne, J. J., Snyder, J., \& Seward, D. (2008). Project management's future: Teaching project management to high school students using project learning. PMI Global Congress Proceedings, Denver, Colorado.

Čulo, K., \& Skendrović, V. (2010). Communication management is critical for project success. Informatologia, 43(3), 228-235.

Çankaya, M. N. (2006). CIO el kitabı. Ankara: Seçkin Yayınları.

De Los Rios, I., Lopez, F. R. ve Garcia, C. P. (2015). Promoting professional project management skills in engineering higher education: Project-based learning strategy. International Journal of Engineering Education, $31(1-B), 1-15$.

Duruhan, K. ve Şan, İ. (2013). Öğretmen adaylarının ÖTMG dersinde proje hazırlama sürecine ilişkin görüşlerinin incelenmesi. The Journal of Academic Social Science Studies: JASSS, 6(7), 379-399.

El-Marashly A. F. (1990) Project management as perceived from Ancient Egyptian Projects. In: Reschke H., Schelle H. (Eds), Dimensions of project management (pp:). Springer, Berlin, Heidelberg.

ETDME: Educational Technology Division Ministry of Education (2006). Project-based learning handbook: Educating the millennial learner. Kuala Lumpur, Malaysia: Educational Technology Division Ministry of Education.

eTwinning. (2005). eTwinning Avrupa Birliği Okul Projeleri. https://www.etwinning.net/tr/pub/projects.htm

Erdem, M ve Akkoyunlu, B. (2002). İlköğretim sosyal bilgiler dersi kapsamında beşinci sınıf öğrencileriyle yürütülen ekiple proje tabanlı öğrenme üzerine bir çalışma. İlköğretim Online, l(1), 2-11.

Ersoy, A. (2007). Illköğretim beşinci sinıfta teknoloji destekli proje tabanlı öğrenme uygulamaları. Anadolu Üniversitesi Eğitim Bilimleri Enstitüsü, Eskişehir.

Fioravanti, M. L., Sena, B., Paschoal, L. N., Silva, L. R., Allian, A. P., Nakagawa, E. Y., Souza, S. R., Isotani, S. ve Barbosa, E. F. (2018). Integrating project based learning and project management for software engineering teaching: An experience report. In 49th ACM Technical Symposium on Computer Science Education, 806-811.

Gordon, J., Halasz, G., Krawczyk, M., Leney, T., Michel, A., Pepper, D., Putkiewicz, E. ve Wisniewski, J. (2009). Key competences in Europe: Opening doors for lifelong learners across the school curriculum and teacher education. CASE Network Report. No. 87. Warsaw: Center for Social and Economic Research.

GSB: T.C. Gençlik ve Spor Bakanlığı Gençlik Projeleri Destekleme Programı. (2018). https://gpdp.gsb.gov.tr/

Gültekin, M. (2005). The effect of project based learning on learning outcomes in the 5th grade social studies course in primary education. Educational Sciences, Theory and Practice, 5(2), 548-557.

Hernández-Ramos, P. ve De La Paz, S. (2009). Learning history in middle school by designing multimedia in a project-based learning experience. Journal of Research on Technology in Education, 42(2), 151-173.

Hutchison, D. (2015). Project based learning: Drawing on best practices in project management. WHAT WORKS? Research into Practice, 60, 1-4. 
Karasar, N. (2006). Bilimsel araştırma yöntemleri. Ankara: Nobel Yayınları.

Korkmaz, H. (2002). Fen ĕgitiminde proje tabanlı öğrenmenin yaratıcı düşünme, problem çözme ve akademik risk alma düzeylerine etkisi (Basılmamış doktora tezi). Hacettepe Üniversitesi, Ankara.

Korkmaz, H. ve Kaptan, F. (2001). Fen eğitiminde proje tabanlı öğrenme yaklaşımı. Hacettepe Üniversitesi Eğitim Fakültesi Dergisi, 20, 193-200.

KOSGEB: T.C. Küçük ve Orta Ölçekli İşletmeleri Geliştirme ve Destekleme İdaresi Başkanlığı (2018). KOSGEB Girişimcilik Destek Programı. https://www.kosgeb.gov.tr/site/tr/genel/destekler/6312/girisimcilik-destekleri

Krajcik, J. ve Blumenfeld, P. (2005). Project-Based Learning. In R. Sawyer (Ed.), The Cambridge Handbook of the Learning Sciences (Cambridge Handbooks in Psychology, pp. 317-334). Cambridge: Cambridge University Press.

Larmer, J., Mergendoller, J. R. ve Ross, D. (2015). Setting the standard for project based learning: A proven approach to rigorous classroominstruction. Alexandria, VA, USA: Association for Supervision and Curriculum Development.

LATCA: Lee A. Tolbert Community Academy. (2008). Project Management Curriculum Unit (Grades 7-8). LATCA: Kansas City.

Luthra, A. ve Dahiya R. (2015). Effective leadership is all about communicating effectively: Connecting leadership and communication. International Journal of Management \& Business Studies, 5(3).

MEB: T. C. Milli Eğitim Bakanlığı. (2018). MEB Uluslararası Robot Yarışması. http://robot.meb.gov.tr/

Mergendoller, J., Markham, T., Ravitz, J., Larmer, J. (2006). Pervasive management of project based learning: Teachers as guides and facilitators. In C. Evertson \& S. Weinstein (Eds.), Handbook of classroom management: Research, practice, and contemporary issues (pp. 583-615). Mahwah, NJ: Erlbaum.

Morgan, J., Zhan, W. ve Leonard, M. (2013). K-12 project management education: NASA Hunch Projects. American Journal of Engineering Education, 4(2), 105-118.

Musa, F., Mufti, N., Latiff, R. A. ve Amin, M. M. (2011). Project-based learning (PjBL): inculcating soft skills in 21st century workplace. Procedia - Social and Behavioral Sciences, 59(2012), 565-573.

OECD: Organization of Economic Co-operation and Development. (2017). Future work and skills. 30.09.2018 https://www.oecd.org/els/emp/wcms_556984.pdf

Özdener, N. ve Özçoban T. (2004), Bilgisayar eğitiminde çoklu zeka kuramına göre proje tabanlı öğrenme modelinin öğrenci başarısı üzerine etkisi. Kuram ve Uygulamada Eğitim Bilimleri, 4(1), 147-170.

P21: Partnership for 21st Century Skills. (2015). Bringing project management into the school transformation conversation.http://www.p21.org/storage/documents/PMIEFToolkit/pmief_toolkit_print_final_web.pdf adresinden 12.05.2018 tarihinde alınmıştır.

P21. (2011). Professional Development for the 21st Century. 02.08.2018 tarihinde aşağıdaki adresten edinilmiştir: http://www.p21.org/storage/documents/ProfDev.pdf

P21. (2009). P21 Framework definitions. 12.05.2018 tarihinde aşağıdaki adresten edinilmiştir:

http://www.p21.org/storage/documents/P21_Framework_Definitions.pdf

P21 ve PMI-EF. (2014). 21 st century skills map - project management for learning. Newtown Square, USA.

Pearlman, B. (2010). Designing new learning environments to support 21 st century skills. In: Bellanca, J., Brandt R. (Eds), 21 st century skills rethinking how students learn (pp:). Bloomington, IN: Solution Tree Press.

Pinto, J. K. (2010). Project management: Achieving competitive advantage. Boston, MA: Pearson Education.

PMI: Project Management Institute. (2013). A Guide to the project management body of knowledge. Project Management Institute (5th eds.), Newtown Square, USA.

PMI-EF: Project Management Institute - Educational Foundation. (2007). Project management skills for life. Newtown Square, USA: The Project Management Institute.

PMI-EF. (2013). Project management toolkit for youth. Project Management Institute, Newtown Square, USA.

PMI-TR: Project Management Institute - Turkey Republic. (2009). Proje yönetimi bilgi birikimi kllavuzu. İstanbul: PMI-TR. 
PRODES: T.C. İçişleri Bakanlığı Proje Destek Sistemi. (2018). Sivil toplum kuruluşları için proje yardımları. https://www.dernekler.gov.tr/prodes.aspx

Rajkumar, S. (2010). Art of communication in project management. Paper presented at PMI® Research Conference: Defining the Future of Project Management, Washington, DC.

Sözer, Y. (2017). Tübitak ortaöğretim öğrencileri araştırma projeleri yarışmasına katılan öğrencilerin edindikleri kazanımların değerlendirilmesi. Electronic Journal of Education Sciences, 6(11), 49-77.

Standish Group. (2014). Chaos report. www.projectsmart.co.uk/white-papers/chaos-report.pdf adresinden 08.02.2016 tarihinde erişilmiştir.

Suvacı, E. (2013). Proje ve proje yönetimine giriş. H. Durucasu (Ed.), Proje yönetimi içinde (s.2-19). Eskişehir: Anadolu Üniversitesi Yayınları.

Tatlı, Z. (2016). Proje geliştirme sürecine dair öğretmen görüşleri *. YYÜ Eğitim Fakültesi Dergisi (YYU Journal Of Education Faculty), 13(1), 631-656.

Trilling, B. (2014). Project management for learning: A foundational guide to applying project management principles and methods to education. Newton Square: Project Management Institute Educational Foundation.

Trilling, B. ve Fadel, C. (2009). 21 st century skills: Learning for life in our times. Francisco: Jossey-Bass.

TUA: Türkiye Ulusal Ajansı. (2018). Türkiye ulusal ajansı teklif çağrıları. ua.gov.tr/programlar/teklif-çağrıları

Tuncer, M. (2009). Proje tabanlı öğrenme ile problem tabanlı öğrenmenin fark ve benzerlikleri. e-Journal of New World Sciences Academy, 4(2), 395-409.

Tübitak. (2018). Tübitak 2204-B Ortaokul Öğrencileri Araştırma Projeleri Yarışması 2019 Yılı Çağrı Duyurusu. http://www.tubitak.gov.tr/sites/default/files/2750/ortaokul_ilan_2019.pdf

Uyanık, M. (2012). Tümevarım meselesi - İBN SÎNÂ merkezli yeni bir okuma -*. Hitit Üniversitesi Ilahiyat Fakültesi Dergisi, 11(21), 195-230.

Uysal, Ö. (2016). Harmanlanmış öğrenme ortamında proje tabanlı öğrenmenin gerçekleştirilmesi. Açıköğretim Uygulamaları ve Araştırmaları Dergisi (AUAd), 2(2), 89-113.

Uysal Ö. ve Lepcha S. D. (2016). Integration of project management in project based learning. International Journal on Recent and Innovation Trends in Computing and Communication, 4(3), 369-377.

Vatansever Bayraktar, H. (2015). Proje tabanlı öğrenme yaklaşımı. Uluslararası Sosyal Araştırmalar Dergisi, 8(37). 709-718.

Watt, A. (2014). Project management. https://opentextbc.ca/projectmanagement/ adresinden 12.05.2018 tarihinde alınmıştır.

Yalçın, S. A., Turgut, Ü. ve Büyükkasap, E. (2009). Proje tabanlı öğretim yönteminin öğrencilerin elektrik konusu akademik başarılarına, fiziğe karşı tutumlarına ve bilimsel işlem becerilerine etkisinin incelenmesi. International Online Journal of Educational Sciences, 2009, 1(1), 81-105.

Yeşilay. (2016). Yeşilay proje destek programları. https://www.yesilay.org.tr/tr/projeler/destek-programlari

YTB: Yurtdışı Türkler ve Akraba Topluluklar Başkanlığı Hibe Destek Programları (2017). https://www.hibedestek.com.tr/tag/ytb/ 